\title{
REFLEXÃO COMPARTILHADA NA FORMAÇÃO CONTINUADA DE PROFESSORES DE CIÊNCIAS: RELATO DE EXPERIÊNCIA ENVOLVENDO RELAÇÕES CTS
}

\author{
Fernando Cesar Ferreira ${ }^{1}$ \\ Lenice Heloisa de Arruda Silva²
}

\section{RESUMO}

Ações de formação continuada de professores ainda necessitam de discussões, no que se refere às metodologias, conteúdos veiculados, vínculos dessas ações com o desenvolvimento profissional dos docentes e com o projeto da escola. Contudo, como instrumentalizar o professor para que ele construa uma postura permanentemente crítica? Refletir sobre possíveis respostas a essa questão constitui o propósito deste artigo. Para isso é apresentado um recorte, na forma de relato de experiência, de um curso de formação continuada oferecido por professores da UFGD para um grupo de quarenta e cinco professores de Ciências de escolas públicas de Dourados, MS. Durante o curso, procuramos evidenciar, através da reflexão compartilhada, como, no ensino de Ciências, processa-se a articulação entre os conteúdos e questões Ciência, Tecnologia e Sociedade (CTS). Neste relato de um dos encontros, os conteúdos discutidos são próximos ao ensino de Física: uso de cartões eletrônicos e magnéticos.

Palavras-chave: Formação continuada; Ensino de Ciências; Ensino Fundamental.

\section{SHARED REFLECTION IN CONTINUOUS TRAINING OF SCIENCE TEACHERS: REPORT INVOLVING CTS RELATIONS}

\begin{abstract}
Continued training activities for teachers still require discussions regarding the methodologies, the disclosed content, the links of these actions to the professional development of teachers and school project. However, how would instrumentalize teacher to build herself/himself a permanently critical attitude? Searching some reflections on possible answers to this question is the purpose of this article. Thereunto, a cut is presented as an experience report from a continuing education course offered by UFGD teachers to a group of forty-five public school teachers of science of Dourados, MS. During the course we seek to show, through shared reflection, how the science teaching takes place in the articulation between the subject content and CTS issues. In this experience report, the contents were near to the Physics teaching, focusing on the use of electronic and magnetic cards.
\end{abstract}

Keywords: Continuing training; Science teaching; Elementary school.

\footnotetext{
1 Licenciado em Física pela UFPR. Doutorado em Educação pela Faculdade de Educação da USP (2004). Professor adjunto na Faculdade de Ciências Exatas e Tecnologia da Universidade Federal da Grande Dourados. Professor do Mestrado Nacional Profissional em Ensino de Física, polo UFGD. Atua na área de Educação, com ênfase em formação de professores de ciências e física. E-mail: <fernandoferreira@ufgd.edu.br>

2 Licenciada em Ciências Biológicas pela Universidade Federal de Mato Grosso do Sul, Doutorado em educação pela Universidade Metodista de Piracicaba (2004). Professora Adjunta da Universidade Federal da Grande Dourados. Professora do Mestrado em Ensino de Ciências da Universidade Federal de Mato Grosso do Sul. Atua na área de Educação, com ênfase em formação de professores de ciências e biologia. E-mail: <leniceheloisa@gmail.com>
} 


\section{REFLEXIÓN COMPARTIDA EN LA FORMACIÓN CONTINUADA DE PROFESORES DE CIENCIAS: REPORTE DE EXPERIENCIA INVOLUCRANDO RELACIONES CTS}

\section{RESUMEN}

Acciones de formación continuada de profesores todavía necesitan discusiones en el que se refiere a metodologías, contenidos, vínculos de esas acciones con el desarrollo profesional de docentes y con el proyecto de la escuela. Sin embargo, ¿cómo instrumentalizar el profesor para que pueda construir una posición permanentemente crítica? Reflexionar sobre posibles respuestas para esa cuestión es el propósito de este artículo. Para ello es presentado un recorte en forma de reporte de experiencia de un curso de formación continuada ofrecido por profesores de la UFGD para un grupo de cuarenta y cinco profesores de Ciencias de escuelas públicas de Dourados, MS. Durante el curso, fue procurado evidenciar, por medio de reflexión compartida, cómo se procesa, en el enseño de Ciencias, la articulación entre contenidos y cuestiones CTS. En este reporte de uno de los encuentros, los contenidos discutidos son próximos de la enseñanza de física: uso de tarjetas electrónicas y magnéticas.

Palabras-clave: Formación continuada. Enseñanza de Ciencias. Educación primaria.

\section{Introdução}

A fragmentação do saber tem representado uma tendência fundamental para a construção e aquisição do conhecimento científico no âmbito do paradigma da ciência moderna, considerado paradigma dominante na atualidade, tendo como base a concepção de que a redução dos fenômenos, em partes cada vez menores, proporcionaria ao indivíduo compreensão do todo e, consequentemente, domínio sobre a natureza. Essa tendência à fragmentação gera/gerou uma visão dualista/dicotômica/maniqueísta de conhecimento, que tem prevalecido, principalmente em termos escolares, porque distingue cabalmente sujeito/objeto, observador/observado, teoria/prática, individual/social, mente/corpo, objetivo/subjetivo, individual/coletivo, causa/efeito e, subjazendo a essas, uma dissociação crucial entre conhecimento científico/senso comum. Fatos decorrentes do paradigma dominante (KUHN, 1975), mesmo apresentando aspectos positivos, promoveram a crise que se instalou no seu interior, pois, à medida que aumentava o volume e o aprofundamento de conhecimentos nas áreas do saber, elevaram-se as limitações de tal paradigma, expondo suas insuficiências estruturais e a fragilidade dos pilares que o fundamentam. Essa crise é o resultado interativo de uma pluralidade de condições distintas entre condições teóricas e condições sociais. Esse paradigma estruturou-se sobre alguns pilares e, entre eles, há o pilar da emancipação e da libertação, mas as condições de seu desenvolvimento permitiram que 
esse pilar fosse absorvido pelo pilar da regulação. Com isso prevaleceu amplamente a racionalidade técnica ou a racionalidade cognitiva-instrumental (SANTOS, 2001). Por meio dessa racionalidade, a produção da ciência passou a ser superespecializada, fragmentada, e o ideal de dominação da natureza pelo conhecimento acabou proporcionando sua exploração até a exaustão. São consequências disso as catástrofes ecológicas, os erros profissionais, a guerra pelos mercados, a exclusão social e outros problemas contemporâneos.

A construção histórica dos conhecimentos científicos reflete-se nos currículos escolares: eles são os mapas onde esse território arrasado pela fragmentação fica mais evidente (GALLO, 2000). Assim, é no âmbito escolar que essa problemática mais se sobressai, pois o conhecimento científico veiculado nesse âmbito pode ser concebido como um conhecimento inexequível, que parece deixar de resolver problemas cotidianos, de ampliar os horizontes cognitivos, bem como deixar de promover a emancipação dos sujeitos que recebem a educação científica escolar. Isso porque os conteúdos de ensino como amostras de conhecimento têm, usualmente, se apresentado uniformizantes, excessivamente livrescos, formais, memorialísticos, desvinculados das experiências socioculturais dos sujeitos, vazios de inter-relações com contextos da realidade, a ponto de se configurar um tipo de conhecimento dito escolar, porque somente parece fidedigno na escola. Por isso, o modelo de racionalidade científica e/ou técnica, tão precioso no âmbito do paradigma da ciência moderna, tem sido amplamente questionado e deflagrado reflexões no âmbito da prática educativa, indicando a necessidade de buscar outros fundamentos orientados a uma racionalidade plural. Além disso, tem incentivado propostas de um ensino mais integrado, interdisciplinar, que busque estabelecer relações entre os diversos campos do conhecimento, bem como uma visão mais crítica da relação Ciência/Tecnologia/Sociedade (CTS).

Dentro dessa perspectiva, a formação de professores é a chave para uma educação que atenda um caráter interdisciplinar, tanto para o rol de atividades que terá de desempenhar em sua ação pedagógica, quanto pela necessidade de que seja um agente transformador de sua própria prática. Essa transformação é premente, uma vez que a chamada globalização da economia, acompanhada pelas ondas de inovações tecnológicas, da automação dos processos industriais, exigem do professor e do seu processo de ensino 
muito mais que o domínio dos saberes básicos. Na escola, esse processo deve possibilitar a inserção do aluno no mundo, não para repeti-lo passivamente, mas para que possa intervir de forma crítica, orientando-se por princípios éticos e de cidadania (KUENZER, 2003).

Educação continuada, requalificação profissional e aperfeiçoamento constante são novos valores incorporados à vivência profissional de todas as categorias. O sistema escolar tem buscado responder, nos diversos países, à pressão das inovações tecnológicas, revendo seus resultados, comparando seu desempenho com outros países, reorientando seus projetos pedagógicos. Formação geral sólida, habilidade para lidar com símbolos, iniciativa, capacidade de resolução de problemas, de sentir-se cidadão do mundo são algumas exigências do mercado de trabalho, seja ele formal ou informal (KUENZER, 2003).

Nesse contexto conflitivo e inédito pelas características que apresenta, é fundamental pensar na educação continuada dos docentes de todos os níveis e áreas de ensino. Trata-se de preparar o formador de alunos para uma realidade na qual competitividade e cidadania, eficiência e solidariedade terão que conviver em níveis mais abrangentes (OLIVEIRA, 2002).

Um processo de ensino que se orienta pelo modelo da transmissão-recepção, no qual cabe ao professor transmitir os conteúdos previamente elaborados aos alunos, que assumem um papel passivo de meros receptores, não atende a essa realidade, seja na perspectiva dos que detém o poder político-econômico ou dos que são submetidos a ele. Em uma visão reprodutivista, não se privilegia o desenvolvimento de atividades que favoreçam estes alunos a elaborarem outros/novos conhecimentos, pois são considerados tabula rasa. Alguns estudiosos da relação educação-trabalho chegam a afirmar que nunca as condições socioeconômicas foram tão favoráveis para se falar em educação integral do indivíduo.

Todo o conjunto de situações que buscam preparar o professor para o ensino, em especial de Ciências, durante a formação inicial ou a graduação e, após esta, nas ações de formação continuada, tem mostrado limitações e desafios para superar o modelo de ensino mencionado. De forma geral, ainda não foram criadas condições para mudanças significativas na concepção dos professores sobre o que é o fazer docente em Ciências, nesse novo contexto.

Portanto, ações de formação continuada de professores ainda necessitam de discussões no que se refere às metodologias, aos conteúdos veiculados, aos vínculos dessas 
ações com o desenvolvimento profissional dos docentes e, em uma perspectiva social mais abrangente, com o projeto da escola. Mas, como instrumentalizar o professor para que ele construa uma postura permanentemente crítica e investigativa diante da área de atuação, da sociedade e da sua conduta em sala de aula?

Buscar algumas reflexões, tendo como referência a prática educativa em Ciências, que possam significar respostas a essa questão constitui o propósito deste artigo. Para isso, utilizaremos a experiência por nós vivenciada em um curso de formação continuada de quarenta e cinco professores de Ciências de escolas públicas do município de Dourados, MS, em que procuramos evidenciar, junto com professores, como se processa, no ensino de Ciências, a articulação entre os conteúdos e as questões CTS (AULER; DELIZOICOV, 2006; AULER, 2003; BRITO; PURIFICAÇÃO, 2006; FÉLIX TEZANOS; LÓPEZ PELÁEZ, 1997; STRIEDER; KAWAMURA, 2009; TENREIRO-VIEIRA; VIEIRA, 2005). Neste relato de experiência, os conteúdos trabalhados foram da área de Física, com foco no eletromagnetismo.

\section{Metodologia}

Os dados utilizados neste relato foram obtidos em um encontro, dos dez ocorridos com um grupo de quarenta e cinco professores de Ciências da rede pública de ensino de Dourados, participantes de um curso de formação continuada promovido por professores ligados às áreas de ensino de Física, Química e Biologia da UFGD (Universidade Federal da Grande Dourados). Em cada encontro um professor da UFGD era responsável pela condução do debate. Também estavam presentes alunos da licenciatura em Ciências Biológicas que cursavam a disciplina Prática de Ensino. Procurou-se, assim, criar um espaço de diálogo e reflexão que envolveu professores universitários, professores de Ciências da rede pública e futuros professores (FERREIRA, LOMBA, SILVA, 2015). O curso de formação era uma ação de extensão financiada pelo Edital MEC-ProExt 2009. O Programa de Extensão Universitária (ProExt) tem como objetivo principal apoiar universidades públicas no desenvolvimento de ações de extensão que contribuam para a implementação de políticas públicas.

Esses encontros ocorreram, em geral, uma vez por mês ao longo de 2009. Durante o primeiro semestre, o foco principal foi o debate e reflexão sobre o fazer docente à 
luz de teorias da construção do conhecimento. Essa etapa permitiu conhecer melhor o grupo de professores quanto a aspectos de formação, tempo de trabalho em escolas, posicionamentos e atitudes de seu papel como professor e, simultaneamente, o ajuste dos objetivos estabelecidos para a formação. Já o segundo semestre foi reservado para a discussão de aspectos específicos de conteúdos de Física, Química e Ciências Biológicas. Os temas foram escolhidos a partir de um conjunto sugerido pelos professores das escolas. A participação dos professores das escolas era voluntária e cada um recebeu, ao final da formação, um certificado de participação, que contabilizava as horas de cada encontro em que o professor esteve presente.

A pergunta norteadora para a preparação da discussão sobre o tema eletromagnetismo foi: como integrar conceitos fundamentais do eletromagnetismo em uma perspectiva integradora e contextualizada? A resposta veio na forma de uma discussão sobre cartões magnéticos e eletrônicos usados em bancos, bilhetagem eletrônica e telefones públicos. A discussão foi iniciada com a pergunta: cartões eletrônicos: como utilizar? O foco está nos dilemas que surgem quando o conhecimento científico é conectado a questões sociais, econômicas e éticas.

O trabalho de coleta de informações foi realizado por meio de observações dos registros gravados em vídeo das discussões e intervenções refletivas coletivamente (SILVERMAN, 2009). Deste modo, a construção dos dados ocorreu após várias leituras das transcrições dos depoimentos obtidos. Um fragmento dos depoimentos foi selecionado para ilustrar a conexão com a pergunta norteadora.

\section{Preparação do tema e seus contextos}

Em 2009, o chamado dinheiro de plástico na forma de cartões de débito superou, pela primeira vez, o número de cheques compensados no Brasil. Acumulando aumentos anuais de cerca de 3\% ao ano, os cartões de crédito e débito avançam sobre o uso de cheques, que já recuou 23\% desde 2003 (AGÊNCIA ESTADO, 2009). Movimento semelhante é visto no uso de cartões destinados à bilhetagem eletrônica nos sistemas de transporte público em diversas cidades brasileiras. Este sistema permite a coleta de informações 
utilizadas para aperfeiçoar horários e acertar a quantidade de ônibus para cada linha, em função da demanda ao longo do dia.

O que se nota com esses dois exemplos é o avanço de tecnologias que, até alguns anos atrás, não faziam parte do cotidiano das pessoas e, atualmente, estão fortemente disseminadas por várias camadas da população. Dois questionamentos cabem aqui: (a) como forma de melhor aproveitar seus cartões, o que os usuários devem saber sobre seu funcionamento? (b) Que implicações sociais, econômicas, de segurança e de privacidade podem surgir em decorrência das informações que são armazenadas nos cartões?

A primeira questão trata do conhecimento necessário para entender o funcionamento de diferentes tipos de cartão utilizados atualmente: magnético, com chip, telefônico, etc. Porque um ímã pode danificar um cartão magnético? Como os cartões guardam as informações do usuário? Como o telefone sabe quantos créditos restam no cartão após uma ligação?

A essência do funcionamento desses cartões está na transmissão/coleta de informações, neles contida, por um dispositivo de leitura/gravação. Para os cartões magnéticos, o registro de dados sobre uma faixa magnética utiliza a propriedade de alguns materiais de serem magnetizados de maneira duradoura pela ação de um campo magnético. Os cartões de débito e/ou crédito com chip (também conhecidos como smart cards) possuem um sistema operacional que gerencia as informações do usuário. Sempre que é inserido em um terminal de atendimento ocorre a troca de dados entre o sistema do banco e do cartão. Já o cartão telefônico contém micro fusíveis distribuídos ao longo da sua superfície. Eles são queimados à medida que se gasta tempo nas ligações. Ao colocar o cartão no telefone, um dispositivo magnético verifica a quantidade de micro fusíveis queimados. Quando a chamada telefônica é iniciada, o aparelho recebe o impulso de tarifação da central telefônica. Para cada impulso recebido o aparelho comanda a queima, por meio de corrente elétrica, de um micro fusível específico.

A segunda questão aponta para um debate que se estabelece a partir da preocupação com clonagem de cartões; reconhecimento, pelas administradoras de cartões, de padrões de consumo do cliente/usuário; diminuição da oferta de vagas em determinadas atividades em função da automatização dos serviços (o aumento dos caixas eletrônicos e a 
diminuição de caixas nos bancos é um exemplo disso); questões éticas ligadas ao conhecimento adquirido do funcionamento dos cartões, por exemplo, técnicas para burlar a leitura da quantidade de créditos em um cartão telefônico.

Consideramos que essas duas questões estão íntima e inseparavelmente ligadas, pois, além de constituírem exemplo de problemática CTS, trata-se de preocupação que envolve componente importante para a formação de professores de ensino de Ciências: a perspectiva de questionamento do paradigma dualista/maniqueísta discutido no início deste trabalho. É neste sentido que apresentamos alguns fragmentos de falas de professores para ilustrar aspectos das relações CTS.

\section{O contexto e seus dilemas}

Durante a explicação sobre o funcionamento de cartões telefônicos, bem como de algumas técnicas utilizadas para tentar burlar o sistema de leitura da quantidade de créditos em uma ligação, fez-se a seguinte pergunta aos professores: ao discutir esse tema com seus alunos, é adequado apresentar essas técnicas? Para ilustrar a linha geral do debate que se seguiu, selecionamos um fragmento da discussão. As falas de cada individuo estão indicadas por turnos [T1], [T2] etc.:

[T1] Prof. 1: eu diria que sim. É claro que não vou dizer que é para burlar o sistema.

[T2] Prof. 2: a questão é como que eles [os alunos] compreendem isso. Nós estaríamos burlando o sistema com consciência, então seria falta de ética. E eles estariam burlando pela ignorância.

[T3] Prof. UFGD1: se fosse comigo eu entraria explicando, agora... eu, conscientemente, deixaria de falar... até porque é uma questão se o aluno tem maturidade para entender que isso não é socialmente aceito.

[T4] Prof. UFGD2: dando uma de advogado do diabo... ao conscientemente não discutir essas questões, não estamos privando o aluno de um conhecimento ou de uma possibilidade que permita a ele atuar diante desse sistema? 
[T5] Prof. 3: tem um princípio do Direito que diz que não há lei sem crime anterior. A partir do momento que eu vou praticar determinado ato e eu sei que ele é ilegal... se, por ventura, gerar algumas consequências, eu tenho que estar preparado para essas consequências. A lei existe por que existe o crime [...]. Dentro da sala de aula, até o Ensino Médio, eu acho complicado esse papel do professor, pois nós trabalhamos com alunos que estão matriculados pelo juiz... que são internos. É complicado você tratar algumas questões com algumas pessoas que você já sabe que ela está em um mundo de infrações, de delitos. Então eu, particularmente, teria dificuldade em abrir a discussão.

[T6] Prof. UFGD2: para que a gente não perca o foco, essa discussão é para mostrar a ligação intrínseca e muito orgânica entre um conhecimento científico e um conhecimento... e atitudes e a vivência do sujeito na sociedade [...] esse conhecimento não está desvinculado, não é desinteressado e não é um fim em si mesmo.

Colocada sob a forma de um dilema, a questão não permite pensar o conhecimento científico de forma desligada de suas consequências sobre e na sociedade. Como uma das consequências desse debate, foi possível trazer para a reflexão dos professores da rede pública e da UFGD, tanto o conhecimento científico necessário para compreender algumas tecnologias de informação utilizadas atualmente, quanto um vislumbre de como ocorre o complexo encadeamento com valores éticos nas relações CTS, conforme visto na fala do Prof. 2 em [T2] (ZIMAN, 1979, 1981).

O que esse fragmento parece mostrar, então, é a necessidade de estimular o debate em ações de formação continuada, de forma a construir uma percepção ampliada do fazer docente e das suas ramificações com o conhecimento científico, tecnológico, social, econômico etc. Nas palavras de Kincheloe,

Os professores concordam que é importante induzir os estudantes para pensar criticamente, mas poucos estão seguros de como atingir tal objetivo. Parece óbvio, mas é muito fechado: os professores devem aprender a pensar de forma sofisticada antes que eles possam ensinar os estudantes a fazê-lo (KINCHELOE, 1997, p. 32). 
Neste sentido, a fala do Prof. 3, sobre sua dificuldade em estabelecer relações de conhecimento com um aluno em regime de liberdade assistida [T5], é indicativa dos desafios a serem enfrentados por ações de formação continuada comprometidas com a real melhoria da qualidade da prática docente.

\section{Palavras finais}

Dois pontos devem ser observados. De forma geral, verificou-se que a estratégia de diálogo constante entre os professores da UFGD e os professores da rede municipal durante os encontros minimizou as resistências à participação desses últimos no curso de formação continuada. Rompendo com a forma usual de cursos de formação, este prezou pela participação e intervenção de todos os participantes a cada encontro, permitindo ampliar o leque de possibilidades de discussão sobre o fazer docente.

O segundo ponto é a abertura para questões para além daquelas suscitadas pelo conhecimento científico. Nesse sentido, e especificamente para esse encontro, o uso de cartões eletrônicos como tema gerador proporcionou, tanto aos professores da rede pública quanto aos professores universitários e acadêmicos presentes, a oportunidade de estabelecer um debate acerca dos conhecimentos científicos inerentes ao funcionamento desses cartões, mas também, e mais importante, a abertura ou ampliação da percepção de como são complexas e dinâmicas as relações CTS.

No sentido das profundas ligações entre ciência, tecnologia e sociedade e seus reflexos na Educação Básica e na formação inicial e continuada de professores, entendemos ser importante trazer, como encaminhamento final deste texto, algumas palavras de Paulo Freire:

O progresso científico e tecnológico que não responde fundamentalmente aos interesses humanos, às necessidades de nossa existência, perde, para mim, sua significação. A todo avanço tecnológico haveria de corresponder o empenho real de resposta imediata a qualquer desafio que pusesse em risco a alegria de viver dos homens e das mulheres. [...] Não se trata, acrescentemos, de inibir a pesquisa e frear os avanços, mas de pô-los a serviço dos seres humanos (FREIRE, 2007, p. 49). 
Portanto, não se trata de como a ciência ou a tecnologia influenciam a sociedade, mas de como essa, através dos anseios, necessidades e sonhos das mulheres e dos homens que a formam, molda as condições iniciais e de contorno para o desenvolvimento da ciência e da tecnologia.

Obviamente, há que se refletir em que aspectos os resultados apresentados podem contribuir para que o ensino de eletromagnetismo, por exemplo, seja menos uniformizante, memorialístico e reprodutivista. Entendemos que a discussão problematizadora com os professores sobre o funcionamento de um cartão magnético contribui para a reflexão sobre os problemas do ensino de eletromagnetismo. O problema maior, no entanto, é como fazer isso. Quais os conceitos científicos que devem ser enfatizados? Como? Quais são as principais dificuldades dos alunos e professores? Como ações de formação continuada de professores podem contribuir para a melhoria da prática docente? Tais perguntas precisam ser respondidas a partir dos resultados de mais pesquisas, tanto qualitativas quanto quantitativas. Este parece ser o passo seguinte no processo de compreensão dos possíveis avanços desta metodologia de formação continuada aqui apresentada.

Por fim, cabe lembrar que um dos objetivos do curso de formação foi a criação de espaços que permitam o diálogo franco e o debate crítico. Pretendeu-se, desta forma, estimular a construção de um nexo permanente entre a universidade, o cotidiano da sala de aula, a ciência, a tecnologia e seus desdobramentos na sociedade.

\section{Referências}

AGÊNCIA ESTADO. Brasileiro usa cada vez mais o "dinheiro de plástico". Bem Paraná, [S.I.], 27 abr. 2009. Disponível em: <http://www.bemparana.com.br/noticia/105701/brasileirousa-cada-vez-mais-o-dinheiro-de-plastico>. Acesso em: 22 jul. 2016.

AULER, D. Alfabetização cientifico-tecnológica: um novo "paradigma"? Ensaio pesquisa em educação em ciências, 2003. v. 5, n. 1, p. 69-83.

AULER, D.; DELIZOICOV, D. Ciência-Tecnologia-Sociedade: relações estabelecidas por professores de ciências. REEC, 2006. v. 5, n. 2, p. 8-0.

BRITO, G. DA S.; PURIFICAÇÃO, I. DA. Educação e novas tecnologias. Curitiba: Ibpex, 2006. 
FÉLIX TEZANOS, J.; LÓPEZ PELÁEZ, A. Ciencia, tecnología y sociedad. Madrid: Fundación Sistema, 1997.

FERREIRA, F. C.; LOMBA, K. S.; SILVA, L. H. A. Relações Ciência-Tecnologia-Sociedade (CST): uma reflexão compartilhada entre professores de ciências e pesquisadores. Revista de Ensino de Ciências e Engenharia, v. 6, n. 2, p. 1-16, 2015.

FREIRE, P. Pedagogia da autonomia: saberes necessários à prática educativa. [S.I.]: Paz e Terra, 2007.

GALLO, S. Disciplinaridade e Transversalidade. In: CANDAU, V. M. (Org.). Linguagens, Espaços e Tempos no Ensinar e no Aprender. Rio de Janeiro: DP\&A, 2000.

KINCHELOE, J. L. A Formação do Professor Como Compromisso Político. Porto Alegre: Artes Médicas, 1997.

KUENZER, A. Z. Conhecimento e competências no trabalho e na escola. Educação \& Linguagem, 2003. v. 8, p. 45-68. . Acesso em: 18 jul. 2011.

KUHN, T. S. A estrutura das revoluções científicas. São Paulo: Perspectiva, 1975.

OLIVEIRA, L. C. V. Reflexões sobre as Políticas de Formação de Educadores para as Séries Iniciais do Ensino Fundamental Através da EAD. In: GONÇALVES, J. (Org.). Políticas e Educação - Múltiplas Leituras. São Bernardo do Campo: UMESP, 2002.

SANTOS, B. S. Um discurso sobre as ciências. Porto: Edições Afrontamento, 2001.

SILVERMAN, D. Interpretação de dados qualitativos: métodos para análise de entrevistas, textos e interações. Porto Alegre: Bookman Editora, 2009.

STRIEDER, R. B.; KAWAMURA, M. R. Panorama das pesquisas pautadas por abordagens CTS. Encontro Nacional de Pesquisa em Educação em Ciências, v. 7, 2009.

TENREIRO-VIEIRA, C.; VIEIRA, R. M. Construção de práticas didático-pedagógicas com orientação CTS: impacto de um programa de formação continuada de professores de ciências do ensino básico. Ciência \& Educação (Bauru), ago. 2005. v. 11, n. 2, p. 191-211. . Acesso em: 31 maio. 2012.

ZIMAN, J. Conhecimento público. Belo Horizonte: Itatiaia, 1979.

ZIMAN, J. A força do conhecimento: a dimensão científica da sociedade. Belo Horizonte: Itatiaia, 1981. 
REFLEXÃO COMPARTILHADA NA FORMAÇÃO CONTINUADA DE PROFESSORES DE CIÊNCIAS

Fernando Cesar Ferreira Lenice Heloisa de Arruda Silva

RECEBIDO EM 21 DE FEVEREIRO DE 2015.

APROVADO EM 19 DE SETEMBRO DE 2016. 